\title{
Enhancement the Agglutination of Erythrocytes in Blood Typing Test by Acousto-Optic Technique
}

\author{
Farah Mohammed Ali ${ }^{1}$, Jamal A. Hasan ${ }^{2}$, Eman Ghadhban Khalil ${ }^{3}$
}

\section{Authors affiliations: \\ $1 *)$ Biomedical Engineering \\ Department, Al-Nahrain \\ University, Baghdad-Iraq \\ farah379@yahoo.com}

2) Biomedical Engineering

Department, Al-Nahrain

University, Baghdad-Iraq

drjamal3@yahoo.com

3) Biomedical Engineering

Department, Al-Nahrain

University, Baghdad-Iraq

dr.emankhalil@yahoo.com

\section{Paper History:}

Received: $28^{\text {th }}$ June 2020

Revised: 13 ${ }^{\text {th }}$ Aug. 2020

Accepted: $25^{\text {th }}$ Sep. 2020

\section{Introduction}

The blood is a connective tissue, it is considered transport system, and the main functions are: transport the dissolved gases like oxygen $\left(\mathrm{O}_{2}\right)$ and carbon dioxide $\left(\mathrm{CO}_{2}\right)$ to and from the tissue respectively, nutrient to the cells, hormones from the endocrine glands, and the wastes product to the kidney [1]. Average healthy males have blood volume from 5 to 6 liters, and in females from 4 to 5 liters [2]. The blood consists of cells (Red and White blood cells) and chemical component (Plasma) [3]. The red blood cells (RBCs) or Erythrocytes have specific glycolipid isoantigens structure: A, B, or neither on its

\begin{abstract}
A proposed modern technique for determination the blood group typing by monitoring the agglutination of red blood cells using acoustooptical technique and digital camera. The method based on analysis the digital image of the agglutination process by MATLAB software.

We present an overview of two acousto-optic sensing approaches; the first demonstrates the cuvette approach while the second is the microscope slide approach. The cuvette approach digital image analyzing depends on the green channel distribution of the original image and count the brighten pixels, while the microscope slide approach passes through series of algorithms started with grayscale filter and end with edge detection it counts the different color pixels.

The experimental result shown that it is possible to enhance the determination of blood group typing by using acousto-optical technique in both cases of using isohemagglutinating sera as well as the crossmatch test in a short time and high efficiency compared with the traditional methods.

Keywords: Erythrocytes Agglutination, Blood Group Typing, Acousto-Optics, Image Processing.

$$
\begin{aligned}
& \text { تحسين تخثر كريات الدم المراء لتحديد زمرة الدم بواسطة التقنية السمعية - البصرية } \\
& \text { فرح محمد علي، جال عبد الجبار حسن، ايمان غضبان خليل } \\
& \text { طريقة حديثة مقترحة للإسراع في تحديد زمرة الدم عن طريق مراقبة عملية تخثر كريات الدم الحمر بواسطة }
\end{aligned}
$$

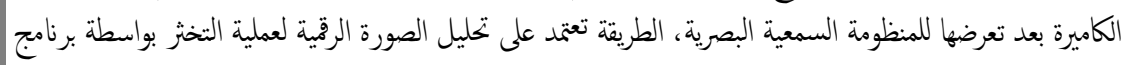

$$
\begin{aligned}
& \text { نقدم طريتتين للاستشعار السمعي البصري، الأول هو طريقة الكيوفيت بنيا الثاني طريقة الشريحة المجهرية. }
\end{aligned}
$$

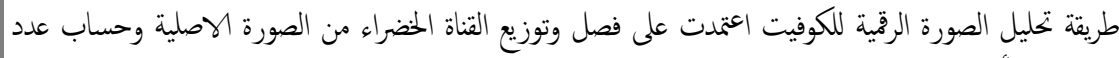

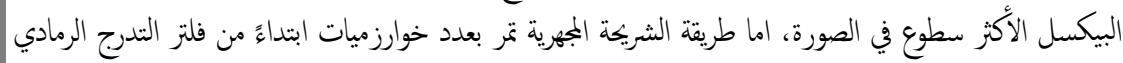

$$
\begin{aligned}
& \text { الى فلتر تحديد الحواف وذلك لتحديد وحساب عدد البيكسل المختلفة اللون. }
\end{aligned}
$$

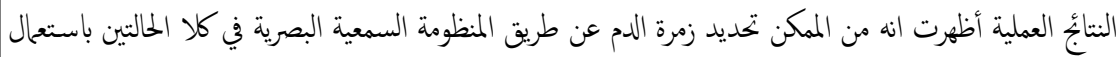

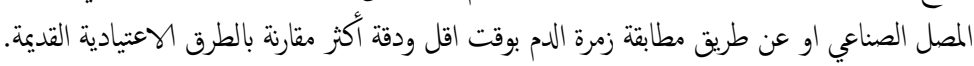

surface, which is responsible for the different types of blood group [4]

Blood group typing refers to the clear apparent chemical reaction between the antigens on the erythrocytes surface and added specific antibodies to supervise the agglutination reaction of blood. The aim of blood group test and cross-matching test are to find the blood compatibility between donor and recipient [5]. The blood type cross-matching test is the compatibility test between the recipient's serum and donors $\mathrm{RBCs}$ that contains $\mathrm{ABO}$ and $\mathrm{RhD}$ antigens, if there is no agglutination reaction, donor blood can safely be transfused to the recipient [6].

NJES is an open access Journal with ISSN 2521-9154 and eISSN 2521-9162

This work is licensed under a Creative Commons Attribution-NonCommercial 4.0 International License 
Which considered one of the most essential tests in medicine before any blood transfusion procedure [7].

Human blood has trillions of red blood cells, which grouped the blood in to four types $\mathrm{A}, \mathrm{B}, \mathrm{O}$, and $\mathrm{AB}$. depending on the nature of the proteins and sugars array that cover the red blood cells surface. The blood can also divide to positive $(+\mathrm{Ve})$ or negative $(-\mathrm{Ve})$ based on the Rhesus $\mathrm{D}(\mathrm{RhD})$ antigen protein [8].

These two-blood group systems $\mathrm{ABO}$ and $\mathrm{Rh}$ classify the human blood to eight groups as $\mathrm{A}^{+}, \mathrm{A}^{-}$, $\mathrm{B}^{+}, \mathrm{B}^{-}, \mathrm{O}^{+}, \mathrm{O}^{-}, \mathrm{AB}^{+}$, and $\mathrm{AB}^{-}[9]$.

There are many traditional methods to identify the blood group typing such as slide method, tube method, microplate technique, and Column $\backslash$ Gel centrifugation [10] [11].

In this work, the study focusses on modern technique to identify the blood group typing automatically by using acousto-optical system. The medical goal of the test is monitoring and enhancing the agglutination process of the erythrocyte while adding the isohemagglutinating sera to identify the blood group in the $\mathrm{ABO}$ and $\mathrm{Rh}$ systems of the blood.

Acousto-optic signal deals with the interaction of sound and light [12]. When an acoustic wave propagates in an optically transparent medium it produces a periodic modulation of index of refraction by the elasto-optical effect, which acts as sinusoidal grating in optical materials, an incident wavelength passing through this grating will diffracted into several directions [13]. Acousto-optic imaging allows revealing optical contrast throughout several centimeters thick biological tissue with a millimeter resolution [14].

\section{Materials and Methods}

The erythrocyte agglutination monitoring system consists of ultrasonic transducer connected to ultrasonic generator, which set perpendicular to the focal wavelength source. Cuvette to hold the blood cell suspension that monitoring by digital camera followed by parallel data processing via computer, as illustrated in figure (1).

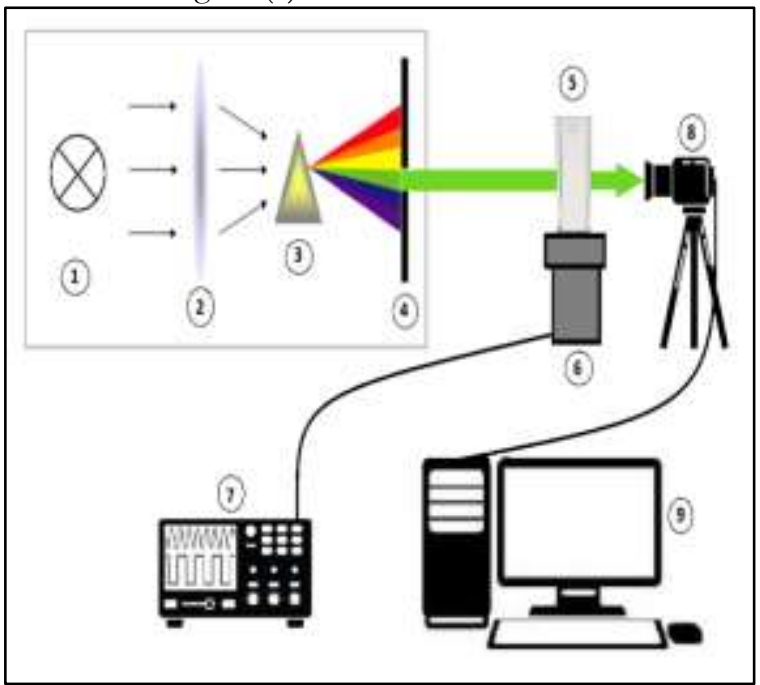

Figure (1): Experimental setup for erythrocyte agglutination monitoring: 1) LED, 2) collimator (lens), 3) monochromatic (prism), 4) wavelength selector (slit); the entire first four component represent the optical part of the system. 5) Cuvette holding the mixture sample, 6) ultrasonic transducer, 7) ultrasonic generator, 8) digital camera, and 9) PC.

\subsection{Blood Samples Preparation:}

Donor blood of all ABO system less than (5ml) collected and the hem-agglutinating sera (Anti-A, Anti-B, and Anti-D) were prepared. The donor blood labeled and centrifuged at $2000 \mathrm{rpm}$ for $5 \mathrm{~min}$, to separate the serum from the erythrocytes [15].] After that, the erythrocyte divided to three new-labeled tubes, washed in the normal saline and centrifuged at the rate $2500 \mathrm{rpm}$ for $3 \mathrm{~min}$ three times. The washed cells re-suspended in the saline to be the ratio (1:78).

The cell suspension in each tube is mixed with hem-agglutinating sera (Anti-A, Anti-B, and Anti-D) respectively in the rate $(1: 2.5)$. Table.1 shows the agglutination reaction between the reagent on the red blood cells surface and the added antibodies to examine the blood group typing.

Table (1): Possible agglutinations reaction between antigens on RBCs surface and the added antibodies. [16].

\begin{tabular}{|c|c|c|c|c|}
\hline Reagent & Anti-A & Anti-B & Anti-D & $\begin{array}{c}\text { Blood } \\
\text { groups }\end{array}$ \\
\hline \multirow{4}{*}{$\begin{array}{c}\text { Agglutination } \\
\text { reaction }\end{array}$} & $\checkmark$ & $\times$ & $\checkmark$ & $\mathrm{A}^{+}$ \\
\cline { 2 - 5 } & $\checkmark$ & $\times$ & $\times$ & $\mathrm{A}^{-}$ \\
\cline { 2 - 5 } & $\times$ & $\checkmark$ & $\checkmark$ & $\mathrm{B}^{+}$ \\
\cline { 2 - 5 } & $\checkmark$ & $\checkmark$ & $\times$ & $\mathrm{B}^{-}$ \\
\cline { 2 - 5 } & $\checkmark$ & $\checkmark$ & $\times$ & $\mathrm{AB}^{+}$ \\
\cline { 2 - 5 } & $\times$ & $\times$ & $\checkmark$ & $\mathrm{O}^{+}$ \\
\cline { 2 - 5 } & $\times$ & $\times$ & $\times$ & $\mathrm{O}^{-}$ \\
\hline
\end{tabular}

\subsection{The Technical Work:}

After preparation of the blood sample, placed in quartz cuvette with dimensions $\left(1.1^{2} \times 5 \mathrm{~cm}^{3}\right)$; the cuvette is a small tube with straight four sides walls, has closed one end and made of a clear transparent material such quartz. It designed to hold liquid samples for spectroscopic analysis.

The cuvette placed on the top of the ultrasonic transducer (KARL DEUTSCH, S12 HB 0.8-3), it was oriented vertically and supplied by function generator (BK PRECISION 4040A) with frequency range from ( 2 to $3 \mathrm{MHz}$ ) and voltage range from (12 to $15 \mathrm{~V}$ ) for time duration less than ( $2 \mathrm{~min})$. At the same time of ultrasonic exposure, a light beam from (VISIBLE SPECTROPHOTOMETER 721) of wavelength $(540 \mathrm{~nm})$ oriented in a perpendicular line with the ultrasonic wave, and directed front the digital camera (Digital Microscope camera) to monitor the agglutination process occurred or not [10].

After switching off the ultrasonic waves, two sensing approaches chosen to analyze the sample image (cuvette and microscope slide). For the cuvette method, digital image captured directly from the cuvette as shown in figure (1). While for the slide method $(20 \mu \mathrm{L})$ taken from the sample in the cuvette directly after switching off the ultrasonic waves by a pipette and drain it on a glass slide to read it by the light microscope and capture digital image.

Both digital images of the cuvette and the slide sample analyzed by MATLAP software to identify 
whether there are agglutination (positive) or not (negative), which is considered a key to the blood group typing.

\subsection{Image Analyzing:}

The image analyses method differs for the cuvette from that of slide sample depending on the thickness of the sample and the illumination passing across it. Each method will be explained separately.

\subsubsection{Cuvette sample analyses:}

This method depends on the distribution of green scale on image pixels $(P)$ and computes the number of brighten one to determine the blood group type [17]. Digital color images taken and the region of interest area selected. First step are taking the $G$ component only from the RGB image, then select brightness threshold pixel value $\left(B_{t h}\right)$ for the selected area, which is considered the comparting value between negative and positive agglutination. On the other hand, number of bright image pixels $\left(B_{p}\right)$ that have the brightness value over than the threshold value calculated as [17]:

$$
B_{p}=\sum\left(P>B_{t h}\right)
$$

Where:

- $\quad B_{p}$ : Total number of bright image pixels.

- $\quad P$ : Total image pixels.

- $B_{t h}$ : Threshold brightness pixel value.

Certain value chosen for number of brighten pixels was selected $\left(B_{\text {limit }}\right)$ to be the limit between negative and positive agglutination depending on the programmer's view. In the case of $\left(B_{p} \geq B_{\text {limit }}\right)$ the results pointed to positive agglutination and message appear "+Ve positive agglutination", otherwise the agglutination are negative "-Ve negative agglutination".

\subsubsection{Slide sample analyses microscopically:}

This method also depends on the brightness level that determine the result, but unlike the first one, it have many steps. After selecting region of interest gray scale mask applied to the digital image of the slide sample, then converting the gray scale image to binary with a certain level, after that applying invers mask followed by edge detection mask.

In this case, the digital image converted to black and white image had pixel values ( 1 or 0$)$.

Computed all the white edges $\left(W_{p}\right)$ pixels of the image and selected certain number of white pixels $\left(W_{\text {limit }}\right)$ to be the limit between negative and positive agglutination, depending on the programmer's view.

If $\left(W_{p} \geq W_{\text {limit }}\right)$ the results show the agglutination is positive and message appear "+Ve positive agglutination", else if $\left(W_{p}<W_{\text {limit }}\right)$ the agglutination is negative "-Ve negative agglutination"[5]

\section{Results and Discussions:}

The experimental work shows that there are positive effects of ultrasonic waves on erythrocytes; it accelerates the agglutination process without initiating hemolysis by reducing the distance between the erythrocytes aggregations. The result of each method will be explained and discussed separately.

\subsection{Cuvette sample analysis:}

The positive agglutination in cuvette sample analysis means the aggregation of red blood cells increases the transparency of the medium, allowing the applied wavelength to pass across the media inside the cuvette and reach the camera (high brightness level), which is appear clearly in fig. 2 and fig.3. While in the negative agglutination, there is no red blood cells aggregation, pattern medium, the hemoglobin in the red blood cells absorbing the entire applied spectrum, which leads to dark (low brightness level) image as shown in Fig.4.

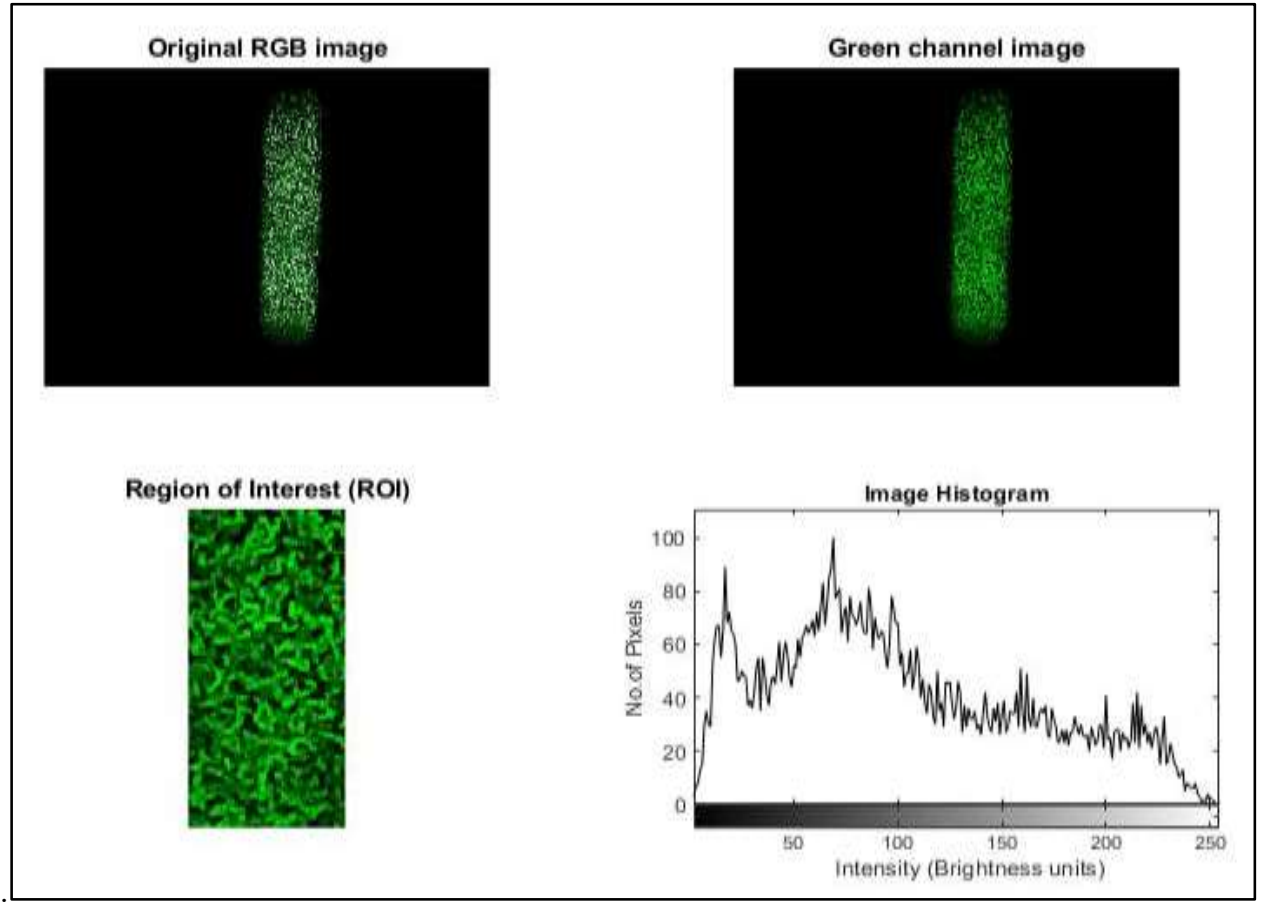

Figure (2): Cuvette sample analyses, shows positive agglutination with ultrasonic effect for (90s) directly after mixing time. Reading after incubation time $30 \mathrm{~min}$ from switching off the ultrasound. 


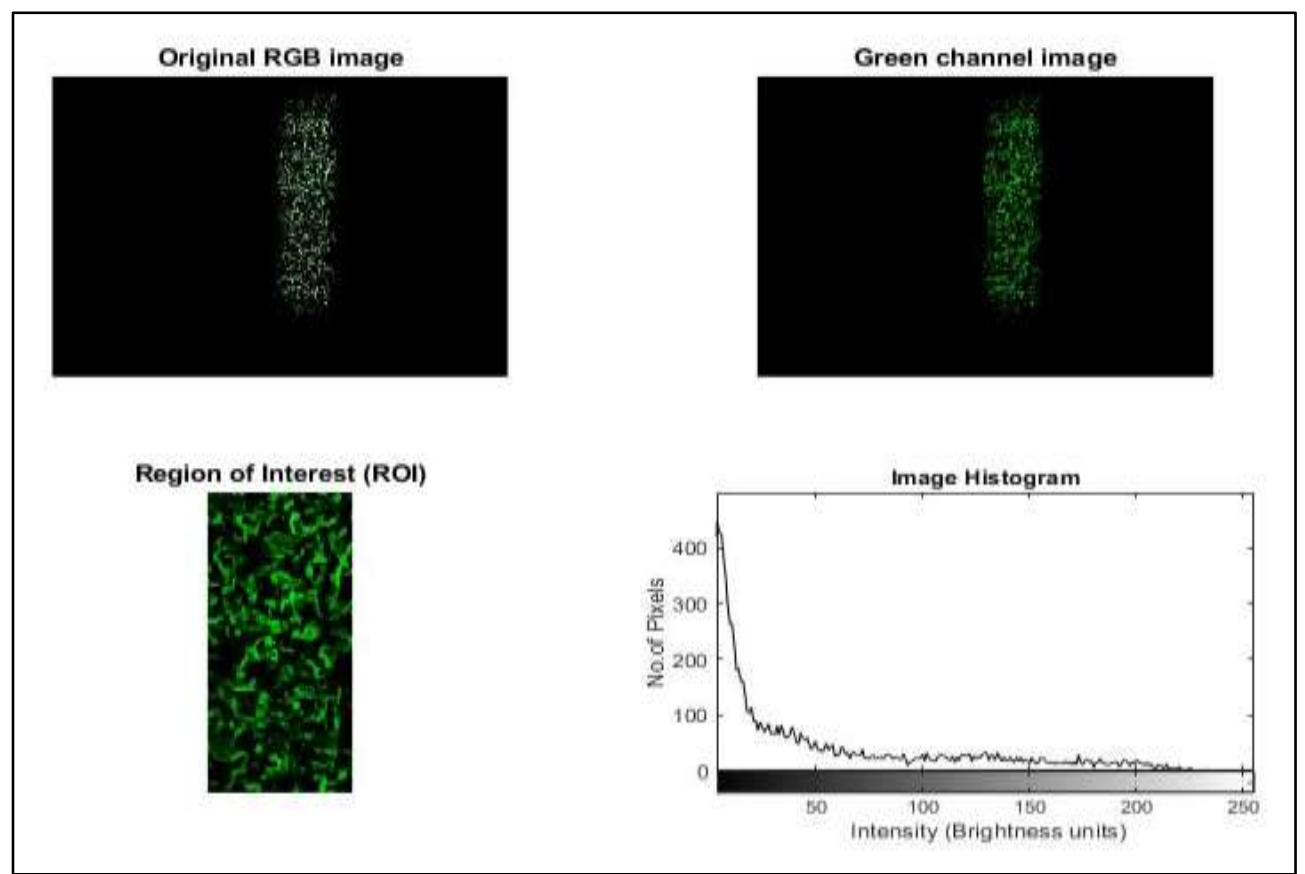

Figure (3): Cuvette sample analyses, shows positive agglutination with ultrasonic effect for (90s) directly after mixing time. Reading after incubation time $30 \mathrm{~min}$ from switching off the ultrasound.

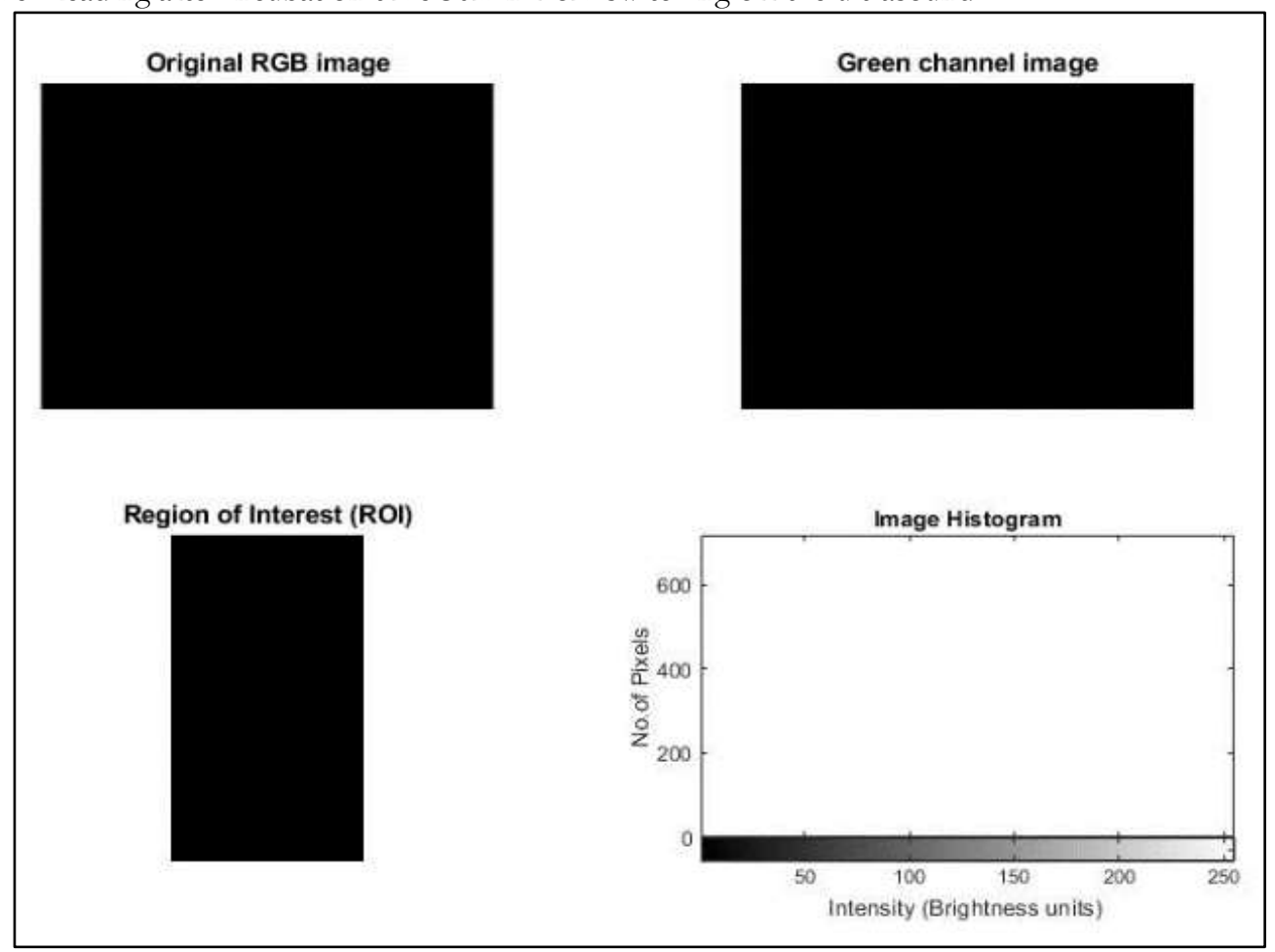

Figure (4): Cuvette sample analyses, shows negative agglutination with ultrasonic effect for (90s) directly after mixing time. Reading after incubation time $30 \mathrm{~min}$ from switching off the ultrasound.

\subsection{The microscope slide analysis:}

Microscope slide analysis shows results within $5 \mathrm{~min}$ from switching off the ultrasonic waves. The results depend on the number of bright edges, the program designed to identify the agglutination when the edges are more than 100 and it varies depending on the specimen volume and digital camera type. Figure 5 shows positive agglutination without ultrasonic effect with edges count 422. While fig.6 shows positive agglutination with ultrasonic effect for the same sample of fig. 5 and it's appeared that the ultrasonic waves have increased the edges to 567 . 


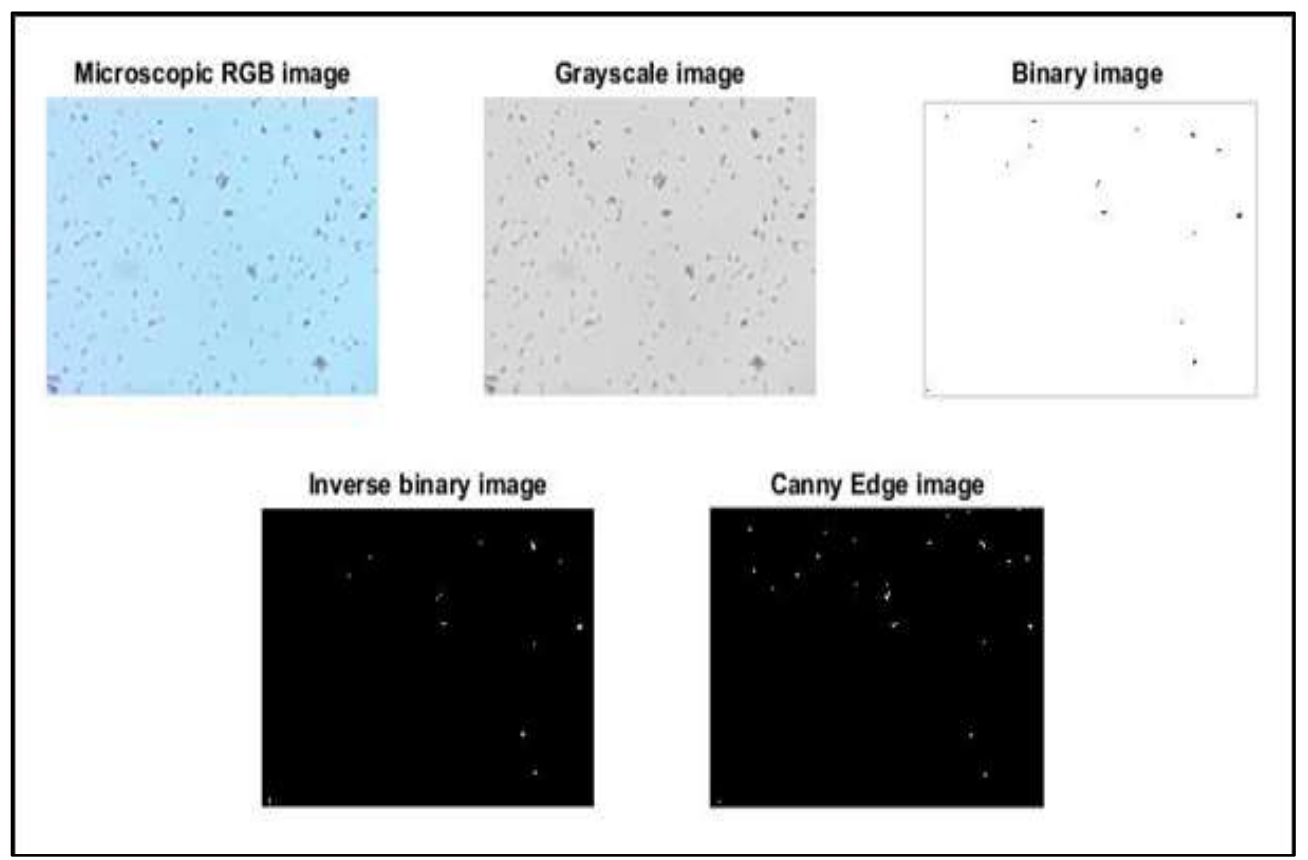

Figure (5): Slide sample analyses microscopically, shows positive agglutination without ultrasonic effect. Incubation time $5 \mathrm{~min}$ after mixing blood suspension $\left(\mathrm{A}^{+}\right)$with Anti-A and the canny edge (white pixels) counts 422 .

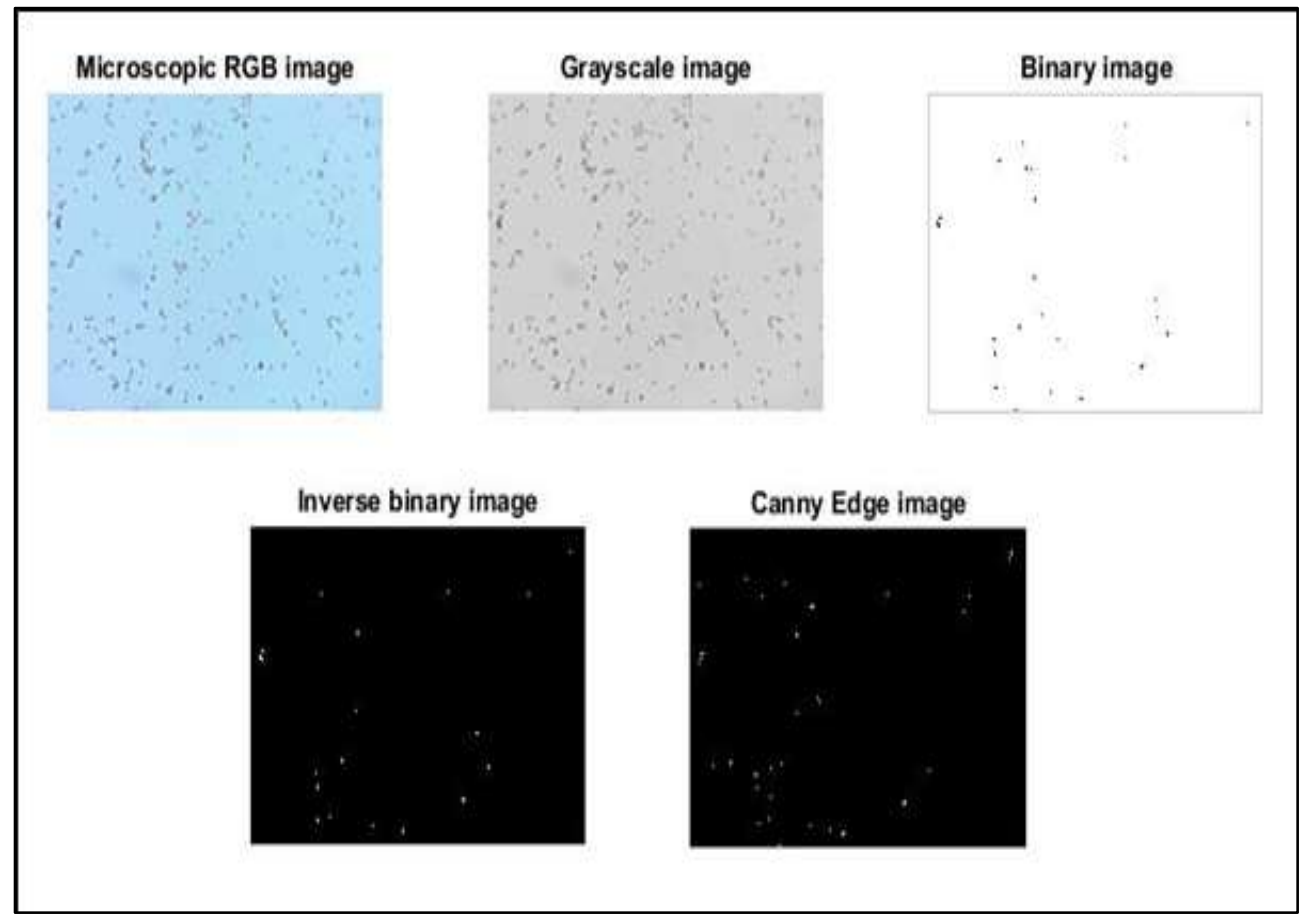

Figure (6): Slide sample analyses microscopically, shows positive agglutination with ultrasonic effect for (90s) directly after mixing time. Incubation time $5 \mathrm{~min}$ from mixing the same sample in figure (5) and the canny edge (white pixels) counts 567 .

\section{Conclusion:}

For this study, the following conclusions are:

- The cuvette method with ultrasonic waves shows the occurrence of the agglutination within (25 to $30 \mathrm{~min}$ ) for blood group typing and crossmatching tests depending on the speed of red cell aggregation. However, without using ultrasonic waves, the agglutination process takes approximately (45min). Whereas the incubation time of the traditional cross-matching tube test takes (30min) then read the result of the sample on the slide under light microscope. For positive agglutination, the digital image has patterns of high brightness level pixels, while in negative agglutination, the digital image appears dark and that means almost all the pixels have low brightness level.

- The slide method monitoring process shows the appearance of aggregation within (4 to $5 \mathrm{~min})$,which is faster than the traditional tube test that takes (15min) according to (Guideline for Standard Operating Procedures in Blood Transfusion Centers \Iraqi Ministry of Health). 
On other hand, it is about five to six times faster than the cuvette method in the presence of acoustic waves due to the small volume of the sample.

The result of digital image analysis depends on the numbers of canny edge detection; the increase of edge numbers means more red cells aggregations, which appear as white pixels, which seem clearly more in the presence of ultrasonic waves.

- Ultrasonic wave enhances and accelerates the appearance of erythrocytes agglutination process, the effective parameters were registered ultrasonic wave frequency was $(2.6 \mathrm{MHz})$ at $(12 \mathrm{~V})$ for $(90 \mathrm{~s})$, for the wavelength of $(540 \mathrm{~nm})$.

- The results show it is possible to design an automated device for determining the blood group typing in a less time based on the acoustooptical technique with various image-analysis software programs.

\section{References:}

[1] Kenneth Saladin, "Anatomy and Physiology: The Unity of Form and Function", $3^{\text {rd }}$ edition, McGraw-Hill Education, New York, p 680, 2003.

[2] Akihisa Nonoyama, "Using Multiwavelength UVVisible Spectroscopy for the Characterization of Red Blood Cells: An Investigation of Hypochromism", University of South Florida, 2004.

[3] Elaine N. Marieb, Katja Hoehn, "Human Anatomy and Physiology ", 11 th edition, Pearson, pp. 634-635, 2018.

[4] Ranadhir Mitra, Nitasha Mishra, Girija Rath, "Blood Groups Systems", Indian Journal of Anesthesia, Vol.58(5): 524-528, 2014.

[5] Geoff Daniels, "Human Blood Groups",2ed edition, Blackwell Science, pp. 1-7, 2002.

[6] Ravindran, G., Joby, T, "Determination and Classification of Blood Types using Image Processing Techniques", International Journal of Computer Applications, Vol.157, No.1, 2017.

[7] Sakib Rahman, Md. Atifur Rahman, "Blood Group Detection Using Image Processing Techniques", BRAC University, 2017.

[8] Laura Dean, "Blood Groups and Red Cell Antigens", National Center for Biotechnology Information (US), MD 20892-6510, 2005.

[9] A. P. Sahastrabuddhe , D. S. D. Ajij, "Blood Group Detection and RBC, WBC Counting: An Image Processing Approach", International Journal of Engineering And Computer Science, Vol. 5, No. 10, pp. 18635-18639, 2016.

[10] Adnan Mujahid and Franz L. Dickert," Blood Group Typing: From Classical Strategies to the Application of Synthetic Antibodies Generated by Molecular Imprinting", Sensors, doi: 10.3390/s16010051, 2016.

[11] Wim Malomgré, Birgid Neumeister, "Recent and Future Trends in Blood Group Typing", Springer-Verlag, DOI 10.1007/s00216-008-24113, 2008.
[12] R.G. Hunsperger, "Integrated Optics: Theory and Technology" $6^{\text {th }}$ edition, Springer, USA \new York, pp.201, 2009.

[13] I. C. Chang, "Handbook of Optics", 2 $2^{\text {nd }}$ edition, Sponsored by Optical Society of America, California/ United States, p12.2, 1995.

[14] Leveque Fort, "Waves and Imaging Through Complex Media ", International Physics School, Cargese/ France, p381, 1999.

[15] A. Chun, P. Birch, K. Ilagan, "A Microplate System for $\mathrm{ABO}$ and $\mathrm{Rh}(\mathrm{D})$ Blood Grouping" ,Transnsion, Vol. 33, No. 5, 1993.

[16] Mehedi HasanTalukder and Md. Mahfuz Reza, "Improvement of Accuracy of Human Blood Groups Determination Using Image Processing Techniques", International Journal of Advanced Research in Computer and Communication, Vol. 4, 2015.

[17] V. A. Doubrovski, M. F. Medvedeva, "The Acousto-Optical Method for Blood Typing (Part 1) Photometric and Statistical Methods for Image Processing", Biomedical Engineering, Vol. 50, No. 1, pp. 10-14, 2016. 